\title{
Quantile Regression for Panel Data: An Empirical Approach for Knowledge Spillovers Endogeneity
}

\author{
Luigi Aldieri ${ }^{1} \&$ Concetto Paolo Vinci ${ }^{2}$ \\ ${ }^{1}$ Department of Business and Economic studies, Parthenope University of Naples, Naples, Italy \\ ${ }^{2}$ Department of Economic and Statistical Sciences, University of Salerno, Fisciano, Italy \\ Correspondence: Luigi Aldieri, Department of Business and Economic studies, Parthenope University of Naples, \\ Via Generale Parisi 13, 80132 Naples, Italy. Tel: 39-081-5474226. E-mail: luigi.aldieri@ uniparthenope.it
}

Received: April 22, 2017

Accepted: May 10, 2017

Online Published: June 15, 2017

doi:10.5539/ijef.v9n7p106

URL: https://doi.org/10.5539/ijef.v9n7p106

\begin{abstract}
The aim of this paper is to investigate the extent to which knowledge spillovers effects are sensitive to different levels of innovation. We develop a theoretical model in which the core of spillover effect is showed and then we implement the empirical model to test for the results. In particular, we run the quantile regression for panel data estimator (Baker, Powell, \& Smith, 2016), to correct the bias stemming from the endogenous regressors in a panel data sample. The findings identify a significant heterogeneity of technology spillovers across quantiles: the highest value of spillovers is observed at the lowest quartile of innovation distribution. The results might be interpreted to provide some useful implications for industrial policy strategy.
\end{abstract}

Keywords: innovation, spillovers, quantile regression, knowledge diffusion

\section{Introduction}

It is widely recognized that knowledge spillovers play a relevant role for firm competitiveness and economic growth. The idea of this work comes from the analysis of most empirical literature about this research topic (Jaffe, 1986; Griliches, 1992; Jaffe, Trajtenberg \& Henderson, 1993; Verspagen, 1997; Jaffe \& Trajtenberg, 2002; Maurseth \& Verspagen, 2002; Bar \& Leiponen, 2012; Malerba, Mancusi, \& Montobbio, 2013; Aldieri, 2013; Aldieri \& Vinci, 2016a and 2016b), where authors consider only the average effect of knowledge spillovers on the dependent variable, represented by innovation or productivity. Since we could assume that slope parameters may vary at various quantiles of the conditional distribution because of firms' heterogeneity, we implement a quantile regression model for panel data.

The results are very interesting in terms of policy implications of the industrial strategy. In particular, it is relevant to evaluate the innovation level of firms with respect to which we explore the spillovers effects. Indeed, the findings identify a significant heterogeneity of technology spillovers across quantiles: the highest value of spillovers is observed at the lowest quartile of innovation distribution.

The paper is structured as follows: Section 2 presents the literature review; in Section 3, we describe the research methodology. The research findings and results are shown in Section 4; finally, Section 5 concludes.

\section{Literature Review}

More recently we can identify various empirical papers based on a more flexible approach, such as quantile regression model, to investigate the relation between inputs and outputs in innovation studies.

Montresor and Vezzani (2015) aim at showing how quantile estimations can make the analysis of the firm's production function better able to deal with the innovation implications of production. They use the EU Industrial R\&D Investment Scoreboard and carry out a quantile estimation of an augmentated Cobb-Douglas production function for a panel of 1000 firms covering the 2002-2010 period. The results of the pooled sample are contrasted with those obtained from the estimates for different groups of economic sectors. They find that returns to scale are bounded by the size of the firm, but to an extent that decreases with the technological intensity of the sector.

Corredoira and Baneryee (2015) introduce technological influence as a variable to measure an invention's direct and indirect impact on the evolution of technology. Findings from quantile regression estimations show 
significant differences in the relationships between antecedents of technological influence and impact.

Coad, Segarra, and Teruel (2016) explore the relationship between innovation and firm growth for firms of different ages. To this end, they use an extensive Spanish Community Innovation Survey sample for the period 2004-2012, by applying panel quantile regressions to study the effect of R\&D activities on firm growth (sales growth, productivity growth and employment growth). They find that young firms face larger performance benefits from $R \& D$ at the upper quantiles of the growth rate distribution, but face larger decline at the lower quantiles.

Benli (2016) uses firm-level data for Turkey's manufacturing firms for the period 2003-2012, to explore the role of firms' absorptive capacity in determining the magnitude of possible benefits from FDI. He develops a conditional quantile regression to allow for different effects of FDI on firms located at different quantiles of productivity. The interesting results reveal that absorptive capacity plays an important role in capturing the positive productivity spillovers from FDI, especially for the firms that have medium and high total factor productivity rates.

Di Cintio, Ghosh, and Grassi (2017) study firms' export and R\&D activities and their effects on growth for a sample of Italian SMEs operating in the manufacturing industry. In particular, quantile regressions show that $\mathrm{R} \& \mathrm{D}$ is associated with higher growth rates.

In this paper, our objective is to investigate the extent to which knowledge spillovers effects are sensitive to different levels of innovation. Research methodology is implemented into two steps. First, we develop a theoretical model in which the core of spillover effect is showed and then we implement the empirical model to test for the results. In particular, we run the quantile regression for panel data estimator (Baker, Powell, \& Smith, 2016).

\section{Research Methodology}

\subsection{Theoretical Model}

This section is devoted to the analysis of the transmission of investment in R\&D generated during the innovation process. We consider, in line with Acemoglu (1996), a simple non-overlapping generation model where each generation of two typologies of agents, living for two periods, is assumed to consist of a continuum of people normalized to unity and with a zero inter-temporal preference rate. People who collect physical capital, are defined investors, while those who provide R\&D may be taken as inventors; all of them are assumed to be risk-neutral.

At time $\mathrm{t}=0$ investors and inventors choose their investments respectively in physical and $\mathrm{R} \& \mathrm{D}$ capital, at time $\mathrm{t}=1$ knowledge production takes place in the form of a partnership of one inventor and one investor, agents will consume all their assets leaving no bequests. In their decisions inventors and investors will consider the stock of respectively $\mathrm{R} \& \mathrm{D}$ and physical capital and then die. The knowledge production takes the functional form:

$$
P_{i, j, t}=A h_{i, t}^{\alpha} k_{j, t}^{(1-\alpha)} \text { with: } 0<\alpha<1
$$

where $\mathrm{A}$ is a positive technology parameter, $\mathrm{P}$ the number of patents (Note 1), hi the i.th inventor level of R\&D, while $\mathrm{kj}$ the physical capital level of the j.th investor.

We assume randomness of the matching technology function, in the sense that each inventor (investor) has the same probability of meeting an investor (inventor), and once a partnership has been formed it is too costly to break it up. The utility functions of the two types of agents will be given by:

$$
\begin{gathered}
U_{i, t}=C_{i, t}-\frac{\lambda_{i}\left(1+l_{i, t}\right)^{(1+\gamma)}}{(1+\gamma)} R \& D_{t-1}, \\
U_{j, t}=C_{j, t}-\frac{\theta_{j}\left(1+e_{j, t}\right)^{(1+\gamma)}}{(1+\gamma)} K_{t-1}
\end{gathered}
$$

where $\lambda_{i}\left(\theta_{j}\right)$ measures the disutility from the $\mathrm{R} \& \mathrm{D}(\mathrm{K})$ investments, $C_{i, t}$ and $C_{j, t}$ capture the consumption levels, assumed to be equal to the expected income of both the agents, li and ej are the investment levels respectively in knowledge and physical capital. Finally $R \& D_{t-1}$ and $K_{t-1}$ are the stock of R\&D and physical capital of the economy inherited from the previous generation, and are respectively defined as:

$$
R \& D_{t-1}=\int_{0}^{1} h_{i, t-1} d t
$$




$$
K_{t-1}=\int_{0}^{1} k_{j, t-1} d j
$$

Moreover, If the i.th inventor R\&D capital level and the J.th investor K capital are given by:

$$
\begin{gathered}
h_{i, t}=(1-\delta)\left(1+l_{i, t}\right) R \& D_{t-1} \\
k_{j, t}=(1-\delta)\left(1+e_{j, t}\right) K_{t-1}
\end{gathered}
$$

(7) (Note 2)

following the standard mainstream on search models, agents incomes derive from a bargaining process leading to a distribution rule according to given proportions $\beta$ and $1-\beta$. From the f.o.c. of the maximization processes we may easily derive:

$$
\begin{gathered}
h_{i, t}=\left\{\frac{A \beta \alpha(1-\delta)^{\gamma+1} R \& D_{t-1}^{\gamma} k_{j, t}{ }^{(1-\alpha)}}{\lambda_{i}}\right\}^{\frac{1}{\gamma+1-\alpha}} \\
k_{j, t}=\left\{\frac{A(1-\beta)(1-\alpha)(1-\delta)^{\gamma+1} K_{t-1}^{\gamma+1-\alpha} h_{i, t}{ }^{\alpha}}{\lambda_{i}}\right\}^{\frac{1}{\gamma+\alpha}}
\end{gathered}
$$

and state what follows:

Result:

Assuming $\lambda_{i}=\lambda$ and $\theta_{j}=\theta$, there exist positive externalities between $R \& D$ and physical capital. When a group of inventors (investors) increase investment in $R \& D$ (physical) capital, other agents, will respond, and the equilibrium rate of return of all subjects will improve. The positive externalities will be greater for lower levels of $R \& D$ (physical) capital.

The above result will imply that in case of different groups of inventors the positive externalities will have different magnitude depending on the initial level of R\&D (Physical) capital implemented to generate patents. In order to measure quantitatively this magnitude, we introduce a quantile regression approach, whose estimates are presented in the following sections.

\subsection{Empirical Approach}

Standard least squares method provides estimates based on the average effect of the independent variable on the average firm. In this analysis, we think that estimation of linear models by quantile regression is preferred. In this case, we may identify two advantages: quantile results are robust to outliers (Buchinsky, 1994) and quantile regression can describe the entire conditional distribution of the dependent variable (as discussed in Coad \& Rao, 2011). Thus, we may assume that error terms are not identically distributed at all points of the conditional distribution and that slope parameters vary at different quantiles of the distribution, in line with the main result of theoretical model in the previous paraFigure. According to Koenker and Bassett (1978), the quantile regression model is:

$y_{i t}=x_{i t}^{\prime} \beta_{\theta}+u_{\theta i t}$ with Quant ${ }_{\theta}\left(y_{i t} / x_{i t}\right)=x_{i t}^{\prime} \beta_{\theta}$

where $\mathrm{y}$ is the dependent variable, $\mathrm{x}$ is a vector of regressors, $\beta$ is the vector of parameters to be estimated, $\mathrm{u}$ is a vector of residuals. Quant $\left.\theta_{i t} / x_{i t}\right)$ identifies the $\theta$ th conditional quantile of y given x.

In particular, we estimate a quantile regression model for panel data (QREGPD) with nonadditive fixed effects (Baker Powell, 2014 and 2016), maintaining the nonseparable disturbance term commonly associated with quantile estimation. The model is developed in an instrumental variable framework. The dataset used in the empirical analysis is the same as in Aldieri \& Vinci (2016a, 2016b). The information on company profiles and financial statements comes from all EU R\&D investment scoreboards editions issued every year until 2013 by the JRC-IPTS (European Commission, 2013). We select an unbalanced panel of 5951 observations for the period 2002-2010. For each firm, information is available for patents (P), the annual capital expenditures (C), the number of employees (L), annual R\&D expenditures (R) and main industry sectors according to the Industrial Classification Benchmark (ICB) at the two digits level. OECD, REGPAT database, January 2012 (Note 3, Note 4) is the second source of information used in this study. This database covers firms' patent applications to the European Patent Office (EPO) including patents published up to December 2011. By using the same dataset relative to international firms as in Aldieri and Vinci (2016a), we apply the quantile regression technique to the following knowledge production function: 


$$
L n P_{i t}=\beta_{0}+\beta_{1} \ln C_{i t}+\beta_{2} \ln L_{i t}+\beta_{3} K_{i t}+\beta_{4} T S_{i t}+\beta_{5} A b C a p_{i t}+u_{i t}
$$

where $P_{i t}$ is the number of patents of firm i at time $t, C_{i t}$ is physical capital of firm $i$ at time $t, L_{i t}$ is the number of employees, $K_{i t}$ represents the stock of knowledge capital computed by perpetual method on R\&D expenditures, $T S_{i t}$ is total stock of spillovers computed as the weighted sum of other R\&D capital stock. For the computation of spillovers, we implement the Jaffe (1986) procedure, based on the proximity between the technological vectors of firms (as in Aldieri, 2011 and 2013; Aldieri \& Vinci, 2016a and 2016b). All variables are measured in logarithmic terms. In Table 1, we display the descriptive statistics of the variables employed for the empirical estimation.

Figure 1 shows the quantiles of dependent variable, $\ln$ (patents), and indicates symmetry.

Table 1. Summary statistics

\begin{tabular}{ccc}
\hline Variable & Mean & Std. Dev. \\
\hline $\ln P$ & 6.25 & 1.646 \\
$\ln L$ & 9.47 & 1.552 \\
$\operatorname{lnC}$ & 7.05 & 1.796 \\
$\ln \mathrm{C}$ & 6.58 & 1.453 \\
$\operatorname{lnTS}$ & 12.89 & 0.428 \\
\hline
\end{tabular}

Note. 5,951 observations.

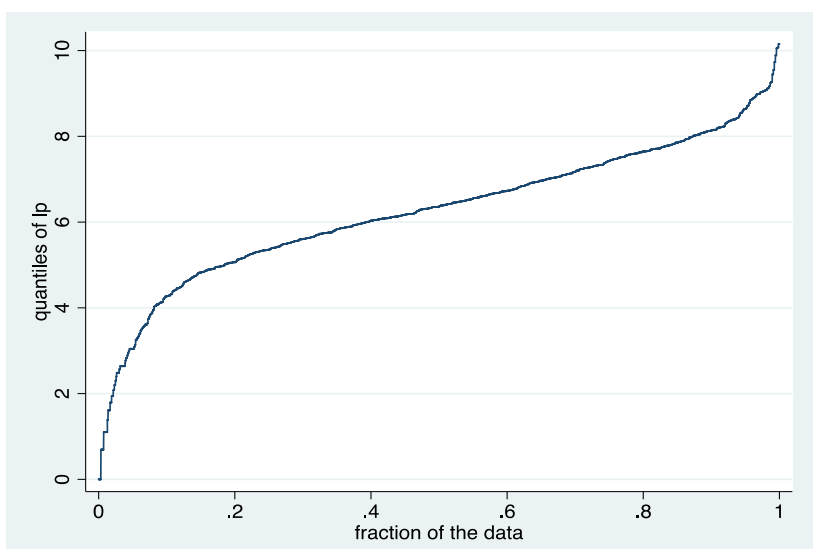

Figure 1. Quantiles of $\ln$ (patents)

\section{Research Findings and Results}

In Table 2, we show the quantile regression with bootstrapped standard errors (Koenker, 2005) results. As expected, size, physical capital, R\&D capital and knowledge spillovers affect positively the innovation procedure of firms at all quantiles of the conditional distribution. The findings identify a significant heterogeneity of technology spillovers across quantiles: the highest value of spillovers is observed at the lowest quartile of innovation distribution.

Table 2. Results: simultaneous quantile regression with bootstrapped standard errors

\begin{tabular}{|c|c|c|c|c|c|c|}
\hline \multicolumn{7}{|c|}{ Dependent variable: $\ln \mathrm{P}$} \\
\hline & Quantile 10\% & S. E. & Quantile 20\% & S. E. & Quantile 30\% & S. E. \\
\hline $\ln L$ & -0.05 & $(0.036)$ & 0.01 & $(0.026)$ & $0.08^{* * *}$ & $(0.028)$ \\
\hline $\ln C$ & $0.42 * * *$ & $(0.038)$ & $0.33^{* * *}$ & $(0.027)$ & $0.25^{* * *}$ & $(0.034)$ \\
\hline $\ln K$ & $0.24 * * *$ & $(0.039)$ & $0.29 * * *$ & $(0.027)$ & $0.33 * * *$ & $(0.027)$ \\
\hline $\operatorname{lnTS}$ & $2.14 * * *$ & $(0.146)$ & $1.44 * * *$ & $(0.089)$ & $1.19 * * *$ & $(0.105)$ \\
\hline pseudo-R2 & 0.42 & & 0.43 & & 0.43 & \\
\hline \multirow[t]{2}{*}{ pseudo- $\mathrm{R}^{2}$} & 0.44 & & 0.42 & & \multicolumn{2}{|c|}{0.42} \\
\hline & Quantile $40 \%$ & S. E. & Quantile 50\% & S. E. & Quantile 60\% & S. E. \\
\hline $\ln L$ & $0.08 * * *$ & $(0.023)$ & $0.08^{* * *}$ & $(0.020)$ & $0.12 * * *$ & $(0.025)$ \\
\hline $\operatorname{lnC}$ & $0.23 * * *$ & $(0.022)$ & $0.22 * * *$ & $(0.021)$ & $0.20 * * *$ & $(0.022)$ \\
\hline $\ln K$ & $0.37 * * *$ & $(0.018)$ & $0.38^{* * *}$ & $(0.020)$ & $0.35^{* * *}$ & $(0.022)$ \\
\hline $\operatorname{lnTS}$ & $1.06^{* * *}$ & $(0.038)$ & $0.99 * * *$ & $(0.060)$ & $0.95^{* * *}$ & $(0.067)$ \\
\hline
\end{tabular}




\begin{tabular}{lllllll}
\hline & Quantile 70\% & S. E. & Quantile 80\% & S. E. & Quantile 90\% & S. E. \\
\hline $\ln \mathrm{L}$ & $0.18^{* * *}$ & $(0.027)$ & $0.19 * * *$ & $(0.023)$ & $0.18^{* * *}$ & $(0.023)$ \\
$\ln \mathrm{C}$ & $0.17 * * *$ & $(0.027)$ & $0.11 * * *$ & $(0.024)$ & $0.10^{* * *}$ & $(0.022)$ \\
$\ln \mathrm{N}$ & $0.32 * * *$ & $(0.022)$ & $0.33 * * *$ & $(0.022)$ & $0.30 * * *$ & $(0.021)$ \\
$\operatorname{lnTS}$ & $0.99 * * *$ & $(0.053)$ & $0.88^{* * *}$ & $(0.042)$ & $1.00 * * *$ & $(0.048)$ \\
pseudo-R2 & 0.43 & & 0.43 & & 0.43 & \\
\hline
\end{tabular}

Note. $* * *$ coefficient significant at the $1 \%$. Country, time and industry dummies are included.

In order to verify statistical variation of coefficients along innovation conditional distribution, we depict a Figureic display of coefficients of interest. In Figure 2, we produce separate Figures for each regressor of the estimated coefficient plotted against the quantile $\mathrm{q}$.

The horizontal lines are the OLS point estimates and confidence intervals (these do not vary with the quantile). The second plot shows that the coefficient on knowledge spillovers is positive, with a much larger effect at lower quantiles.
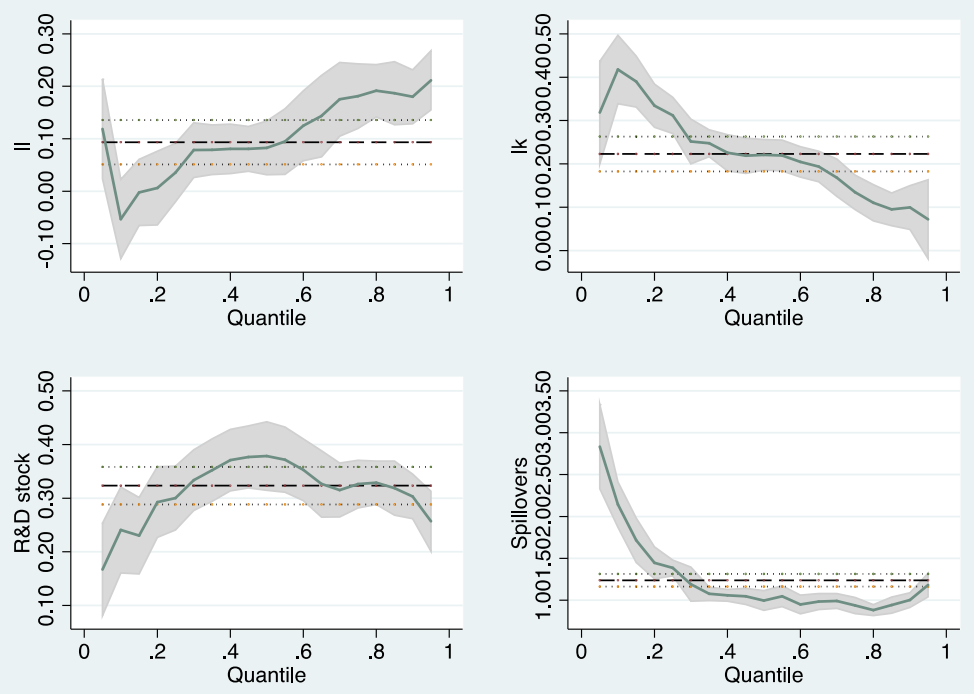

Figure 2. QR coefficients and confidence intervals as quantile varies from 0 to 1

Moreover, we also implement a Wald statistical test to control that coefficients on the spillovers variable have the same value:

Table 3. Wald Test of coefficient equality across different quantiles

\begin{tabular}{cc}
\hline Test result & p-value \\
\hline $\mathrm{F}(8,5921)=12.20$ & Prob $>\mathrm{F}=0.0000$ \\
\hline
\end{tabular}

The null hypothesis of coefficient equality is rejected at a level of 0.05 , by confirming the Figureical analysis.

As discussed in the empirical literature (Parente and Santos Silva, 2016), it is possible to identify intra-cluster correlation in event of data sampled from independent and identically distributed clusters. In our sample, the Parente-Santos Silva test demonstrates the intra-cluster correlation (Note 5). Thus, the consistency of quantile estimator could be questionable. For this reason, we develop a quantile regression with clustered standard errors (Machado, Parente \& Santos Silva, 2011) in Table 4. 
Table 4. Results: quantile regression with robust and clustered standard errors (QREG2)

\begin{tabular}{|c|c|c|c|c|c|c|}
\hline \multicolumn{7}{|c|}{ Dependent variable: $\ln \mathrm{P}$} \\
\hline & Quantile $10 \%$ & S. E. & Quantile 20\% & S. E. & Quantile $30 \%$ & S. E. \\
\hline $\ln L$ & $0.20 *$ & $(0.105)$ & $0.20 * *$ & $(0.080)$ & $0.17 * * *$ & $(0.063)$ \\
\hline $\ln C$ & $0.15^{* *}$ & $(0.079)$ & 0.11 & $(0.094)$ & $0.17 * * *$ & $(0.062)$ \\
\hline $\ln K$ & $0.29 * * *$ & $(0.074)$ & $0.31^{* * *}$ & $(0.104)$ & $0.31^{* * *}$ & $(0.060)$ \\
\hline $\operatorname{lnTS}$ & $2.14 * * *$ & $(0.385)$ & $1.12^{* * * *}$ & $(0.246)$ & $0.94 * * *$ & $(0.083)$ \\
\hline \multirow[t]{2}{*}{ pseudo- $\mathrm{R}^{2}$} & 0.43 & & 0.45 & & 0.45 & \\
\hline & Quantile $40 \%$ & S. E. & Quantile 50\% & S. E. & Quantile 60\% & S. E. \\
\hline $\ln L$ & $0.16^{*}$ & $(0.064)$ & $0.12 *$ & $(0.067)$ & $0.12 *$ & $(0.063)$ \\
\hline $\ln C$ & $0.22 * * *$ & $(0.075)$ & $0.27 * * *$ & $(0.083)$ & $0.25^{* * *}$ & $(0.080)$ \\
\hline $\ln K$ & $0.28 * * *$ & $(0.071)$ & $0.26^{* * *}$ & $(0.059)$ & $0.25^{* * *}$ & $(0.067)$ \\
\hline $\operatorname{lnTS}$ & $0.89^{* * *}$ & $(0.171)$ & $0.85^{* * *}$ & $(0.096)$ & $0.85^{* * *}$ & $(0.131)$ \\
\hline \multirow[t]{2}{*}{ pseudo-R2 } & 0.45 & & 0.45 & & 0.45 & \\
\hline & Quantile 70\% & S. E. & Quantile $80 \%$ & S. E. & Quantile 90\% & S. E. \\
\hline $\ln L$ & $0.15^{* * *}$ & $(0.052)$ & $0.16^{* * *}$ & $(0.050)$ & $0.12 * *$ & $(0.058)$ \\
\hline $\ln C$ & $0.20^{* * *}$ & $(0.064)$ & $0.20^{* * * *}$ & (0.059) & $0.24 * * *$ & $(0.054)$ \\
\hline $\ln K$ & $0.23^{* * *}$ & $(0.058)$ & $0.22 * * *$ & $(0.052)$ & $0.20^{* * *}$ & $(0.036)$ \\
\hline $\operatorname{lnTS}$ & $0.84^{* * * *}$ & $(0.113)$ & $0.81^{* * *}$ & $(0.107)$ & $0.92 * * *$ & $(0.096)$ \\
\hline pseudo-R2 & 0.45 & & 0.45 & & 0.43 & \\
\hline
\end{tabular}

Note. ***, **, * coefficient significant at the $1 \%, 5 \%, 10 \%$ level respectively.

Country, time and industry dummies are included.

As we may observe from Table 4, results of quantile regression concerning knowledge spillovers confirm the previous ones and thus, they are robust with respect to intra-cluster correlation.

Table 5. Results: quantile regression for panel data (QREGPD)

\begin{tabular}{lcccc}
\hline \multicolumn{4}{l}{ Dependent variable: $\ln \mathrm{P}$} & \multicolumn{3}{l}{} \\
\hline $\ln \mathrm{Quantile} 10 \%$ & S. E. & Quantile 20\% & S. E. \\
\hline $\ln \mathrm{C}$ & 0.19 & $(0.261)$ & -1.35 & $(10.56)$ \\
$\ln \mathrm{N}$ & 0.25 & $(0.484)$ & -1.11 & $(10.41)$ \\
$\ln \mathrm{TS}$ & 0.09 & $(0.271)$ & -2.41 & $(13.55)$ \\
pseudo- ${ }^{2}$ & $3.64^{* * *}$ & $(1.246)$ & 0.63 & $(4.203)$ \\
\hline
\end{tabular}

Note. $* * *, * *, *$ coefficient significant at the $1 \%$. Country, time and industry dummies are included..

Instrumental variables: $\mathrm{LnL}(\mathrm{t}-1) ; \ln \mathrm{L}(\mathrm{t}-2) ; \operatorname{lnC}(\mathrm{t}-1) ; \ln \mathrm{C}(\mathrm{t}-2) ; \ln \mathrm{K}(\mathrm{t}-1) ; \operatorname{lnK}(\mathrm{t}-2) ; \ln \mathrm{TS}(\mathrm{t}-1) ; \ln \mathrm{TS}(\mathrm{t}-2)$.

Finally, the endogeneity issue in the implemented model could be questionable because of simultaneity of decision precesses. For this reason, we estimate a quantile regression for panel data (Baker, Powell and Smith, 2016; Powell, 2014 and 2016), where we use lagged explanatory variables as instruments in Table 5. It is sufficient to explore the results of the two quantiles (10\% and 20\%) to verify the robustness of the previous findings.

\section{Conclusions}

In this paper, we investigate firms' innovation, measured by patents (OECD, REGPAT database, 2012), with a particular attention on the role of knowledge spillovers. In order to carry out our analysis, we apply different econometric techniques on an unbalanced panel of 5951 observations for the period 2002-2010. Firms' data relative to three economic areas (the USA, Japan and Europe) come from all EU R\&D investment scoreboards editions issued until 2013 by the JRC-IPTS (European Commission, 2013).

In order to better analyse the relationship between firm's innovation and R\&D spillovers, we study whether such relationship varies along the innovation distribution by applying quantiles regression techniques. In particular, we run a quantile regression model with bootstrapped standard errors (Koenker, 2005) and a quantile regression asymptotically valid under heteroskedasticity and intra-cluster correlation (Machado, Parente, \& Santos Silva, 2011; Parente \& Santos Silva, 2016). Finally, we deal with the endogeneity of variables, by applying the quantile 
regression for panel data (Baker, Powell, \& Smith, 2016; Powell, 2014 and 2016).

Empirical results suggest that R\&D spillovers positively affect firms' innovation. In particular, such effect has a bell shaped pattern along the innovation conditional distribution, with firms whose innovation ranges between values of about $10 \%$ and $20 \%$ exhibiting higher returns from R\&D spillovers, while returns are found to be lower for successive quantiles.

Overall results suggest that $R \& D$ spillovers components help to explain heterogeneity in innovation capacity and might provide useful insights for the design of policy instruments aimed at favouring productivity improvements.

\section{Acknowledgements}

The authors would like to thank Alfredo Del Monte for precious comments and suggestions. The usual disclaimers apply.

\section{References}

Acemoglu, D. A. (1996). Microfoundation for social increasing returns in human capital accumulation. The Quarterly Journal of Economics, 111, 779-804. https://doi.org/10.2307/2946672

Aldieri, L. (2011). Technological and geoFigureical proximity effects on knowledge spillovers: Evidence from the US patent citations. Economics of Innovation and New Technology, 20, 597-607. http://dx.doi.org/10.1080/10438599.2011.554632

Aldieri, L. (2013). Knowledge technological proximity: Evidence from US and European patents. Economics of Innovation and New Technology, 22, 807-819. http://dx.doi.org/10.1080/10438599.2013.788838

Aldieri, L., \& Vinci, C. P. (2016a). Knowledge migration: A cross-national analysis, De Economist, 164, 109-123. https://doi.org/10.1007/s10645-015-9269-5

Aldieri, L., \& Vinci, C. P. (2016b). Technological spillovers through a patent citation analysis. International Journal of Innovation Management, 20(2). https://doi.org/10.1142/S1363919616500286;

Baker, M., Powell, D., \& Smith, T. A. (2016). QREGPD: Stata module to perform Quantile Regression for Panel Data. Statistical Software Components S458157, Boston College Department of Economics.

Bar, T., \& Leiponen, A. (2012). A measure of technological distance. Economics Letters, 116, 457-459. https://doi.org/10.1016/j.econlet.2012.04.030

Benli, M. (2016). Productivity spillovers from FDI in Turkey: Evidence from quantile regressions. Theoretical and Applied Economics, 3, 177-196.

Buchinsky, M. (1994). Changes in the U.S. Wage Structure 1963-1987: Application of Quantile Regression. Econometrica, 62, 405-458. https://doi.org/10.2307/2951618

Chernozhukov, V., Fernandez-Val, I., \& Kowalski, A. E. (2015). Quantile regression with censoring and endogeneity. Journal of Econometrics, 186, 201-221. https://doi.org/10.1016/j.jeconom.2014.06.017

Coad, A., \& Rao, R. (2011). The firm-level employment effects of innovations in high-tech US manufacturing industries. Journal of Evolutionary Economics, 21, 255-283. https://doi.org/10.1007/s00191-010-0209-x

Coad, A., Segarra, A., \& Teruel, M. (2016). Innovation and firm growth: Does firm age play a role? Research Policy, 45, 387-400. https://doi.org/10.1016/j.respol.2015.10.015

Cohen, W. M, \& Levinthal, D. A. (1989). Innovation and Learning: The two faces of R\&D. The Economic Journal, 99, 569-596. https://doi.org/10.2307/2233763

Corredoira, R. A., \& Baneryee, P. M. (2015). Measuring patent's influence on the technological evolution: A study of knowledge spanning and subsequent inventive activity. Research Policy, 44, 508-521. https://doi.org/10.1016/j.respol.2014.10.003

Di Cintio, M, Ghosh, S., \& Grassi, E. (2017). Firm growth, R\&D expenditures and exports: An empirical analysis of Italian SMEs. Research Policy, 46, 836-852. https://doi.org/10.1016/j.respol.2017.02.006

European Commission. (2013). The 2013 EU Industrial R\&D Investment Scoreboard. JRC Scientific and Technical Research series. Retrieved from http://iri.jrc.ec.europa.eu/scoreboard.html

Griliches, Z. (1992). The search for R\&D spillovers. The Scandinavian Journal of Economics, 94, S29-S47. http://doi.org/10.2307/3440244

Jaffe, A. B. (1986). Technological opportunity and spillovers of R\&D: Evidence from firms' patents, profits and market value. American Economic Review, 76, 984-1001. https://doi.org/10.3386/w1815 
Jaffe, A. B., \& Trajtenberg, M. (2002). Patents, citations, and innovations: A window on the knowledge economy. MIT press.

Jaffe, A., Trajtenberg, M., \& Henderson, R. (1993). GeoFigureic localization of knowledge spillovers as evidenced by patent citations. The Quarterly Journal of Economics, 108, 577-598. https://doi.org/10.2307/2118401

Koenker, R. (2005). Quantile regression. New York: Cambridge University Press.

Koenker, R., \& Bassett, G., (1978). Regression Quantiles. Econometrica, 46, 33-50.

Machado, J. A. F., Parente, P. M. D. C., \& Santos Silva, J. M. C. (2011). QREG2: Stata module to perform quantile regression with robust and clustered standard errors. Statistical Software Components S457369, Boston College Department of Economics, revised 07 Feb 2015.

Malerba, F., Mancusi, M. L., \& Montobbio, F. (2013). Innovation, international R\&D spillovers and the sectoral heterogeneity of knowledge flows. Review of World Economics, 149, 697-722. https://doi.org/10.1007/s10290-013-0167-0

Maurseth, P. B., \& Verspagen, B. (2002). Knowledge spillovers in Europe: A patent citation analysis. Scandinavian Journal of Economics, 104, 531-545. https://doi.org/10.1111/1467-9442.00300

Montresor, S., \& Vezzani, A. (2015). The Production function of top R\&D investors: Accounting for size and sector heterogeneity with quantile estimations. Research Policy, 44, 381-393. http://dx.doi.org/10.1016/j.respol.2014.08.005

OECD, REGPAT database. (accessed January 1, 2012). ftp://prese:Patents@ ftp.oecd.org/REGPAT_201301/.

Parente, P. M. D. C., \& Santos Silva, J. M. C. (2016). Quantile Regression with Clustered Data. Journal of Econometric Methods, 5(1), 1-15. https://doi.org/10.1515/jem-2014-0011

Powell, D. (2014). Did the Economic Stimulus Payments of 2008 Reduce Labor Supply? Evidence from Quantile Panel Data Estimation. RAND Labor and Population Working Paper 710-3.

Powell, D. (2016a). Quantile Regression with Nonadditive Fixed Effects. Retrieved from http://works.bepress.com/david_powell/1/

Powell, D. (2016b). Quantile Treatment Effects in the Presence of Covariates. RAND Corporation. Retrieved from http://works.bepress.com/david_powell/4/

Verspagen, B. (1997). Measuring intersectoral technology spillovers: Estimates from the European and US $\begin{array}{lllll}\text { patent office databases. Economic Systems Research, 9, } & \text { 47 }\end{array}$ http://dx.doi.org/10.1080/09535319700000004

\section{Notes}

Note 1 . We assume that patents' benefits are not unlimited because they depend on the law.

Note 2. $\delta$ is the capital depreciation rate

Note 3. See Maraut, Dernis, Webb, Spieazia, and Guellec (2008) for the methodology used for the construction of REGPAT.

Note 4. Please contact Helene.DERNIS@ @oecd.org to download REGPAT database.

Note 5. Parente-Santos Silva test results for intra-cluster correlation can be provided from the authors upon request.

\section{Copyrights}

Copyright for this article is retained by the author(s), with first publication rights granted to the journal.

This is an open-access article distributed under the terms and conditions of the Creative Commons Attribution license (http://creativecommons.org/licenses/by/4.0/). 